\title{
Use, Usability, And Impact of A Tool To Support Conversations About End-of-Life Preferences In Residential Elder Care - A Qualitative Study of Staff Experiences
}

Therese Johansson ( $\square$ therese.johansson@ki.se )

Karolinska Institute

Carol Tishelman

Karolinska Institute

Lars E. Eriksson

Karolinska Institute

Joachim Cohen

Vrije Universiteit Brussel

Ida Goliath

Karolinska Institute

\section{Research Article}

Keywords: Palliative care, Advance Care Planning, Person-centered care, Go Wish cards, Patient-provider communication, Qualitative research, Content analysis

Posted Date: September 13th, 2021

DOI: https://doi.org/10.21203/rs.3.rs-847408/v1

License: (c) (i) This work is licensed under a Creative Commons Attribution 4.0 International License.

Read Full License 


\section{Abstract}

Background: If EOL care is to be person-centred and value-concordant, proactive conversations about individual preferences between residents, relatives, and staff are required. Nevertheless, the prevalence of conversations about preferences for EOL care is still low in residential care homes (RCHs), often relating to staff's perceived lack of skills and confidence. Conversation tools may be useful to support staff in facilitating EOL conversations, but often focus more on documenting treatment priorities than on exploring underlying values and reasoning for preferences. In this study, we use the DöBra cards, the Swedish version of the GoWish cards, to support discussions about EOL care values and preferences in $\mathrm{RCHs}$, and explore staff perspectives on use, usability, and impact.

Methods: This qualitative study was based on data generated from two participatory action research processes in which RCH staff tested and evaluated use of DöBra cards in EOL conversations. Data comprise 6 interviews and 8 group meetings with a total of 13 participants from 7 elder care facilities. Qualitative content analysis was performed to identify key concepts in relation to use, usability, and impact of the DöBra cards with residents and/or relatives.

Results: Based on participants' experiences of using the DöBra cards as an EOL conversation tool in $\mathrm{RCHs}$, we identified three main categories in relation to its usefulness. Outcomes of using the cards (1) included the outlining of content of conversations and supporting connection and development of rapport. Perceived impact (2) related to enabling openings for future communication and aligning care goals between stakeholders. Use and usability of the cards (3) were influenced by supporting and limiting factors on the personal and contextual level.

Conclusions: This study demonstrates how the DöBra cards was found to be useful by staff for facilitating conversations about EOL values, influencing both the content of discussion and interactions between those present. The tool encouraged reflection and interaction, which staff perceived as potentially helpful in building preparedness for future care-decision making. The combination of providing a shared framework and being adaptable in use appeared to be key features for the DöBra cards usability in the $\mathrm{RCH}$ setting.

\section{Background}

In many developed countries, residential care homes ( $\mathrm{RCHs}$ ) are increasingly major providers of end-oflife (EOL) care for older people [1]. Given the high prevalence of palliative care needs in RCHs [2], it is important to identify appropriate goals of care early in the care trajectory [3]. Proactive conversations about values and preferences for future EOL care (henceforth: EOL conversations) may be a way to achieve this, as they have been shown to support value-concordant EOL care provision $[4,5]$ and reduce decisional conflict and uncertainty among residents' family members [6]. EOL conversations are integral in Advance care planning (ACP), a process that aims to identify, discuss, and document preferences for 
future care [7]. Yet, considerable variability in ACP delivery and scope of EOL conversations limits strong conclusions regarding its impact on EOL care [8], particularly for older people [9].

Lack of communication about EOL issues in RCHs has been shown to negatively affect perceptions of care quality by e.g. reducing trust in staff's knowledge about residents' care preferences [10], whereas repeated open dialogue can allow time for residents and relatives to process information and more carefully consider care goals [11]. However, EOL conversations between staff, residents and/or relatives are infrequent in the RCH context [12], with identified barriers including insufficient skills, experience, and confidence among RCH staff $[13,14]$. There is thus a considerable demand for means to support staff in initiating and facilitating EOL conversations in practice. Purely didactic educational programmes, however, have been found to have limited effect, with self-efficacy more strongly associated with staff engagement in EOL conversations than knowledge alone [15, 16], suggesting that competence-building initiatives should include steps to increase confidence among staff.

Common tools for EOL conversations may involve scripts or check-lists that staff follow in discussing and documenting care preferences [17], or are designed as decision aids or for information-sharing, e.g. explaining prognosis and treatment alternatives $[18,19]$. These risk supporting unidirectional communication and discussions of medical treatment options rather than stimulating and directing broader reflection about EOL preferences. In contrast, conversation tools in the form of cards have been developed to support both reflection and interactive discussion about values and preferences for EOL care (e.g. Hello [20], Heart to Heart [21], and GoWish cards). In this study, we use, the DöBra cards, the translated and adapted Swedish version of the U.S. English-language GoWish cards [22] as they cover various physical, practical, existential, and social matters of potential importance for guiding EOL care provision. The English-language GoWish cards have been used to discuss EOL care preferences in various clinical settings $[23,24]$ and the Swedish-language cards were found acceptable and easy-to-use among community-dwelling older people without known palliative care needs [25]. In addition to clarifying care preferences, the Swedish DöBra cards have been shown to elicit information about underlying values [26] as well as promote interest and confidence in EOL conversations among elder care staff, indicating that the tool has potential to support educational initiatives [27]. Nevertheless, the cards had not been tested with residents and/or relatives in RCHs prior to this study.

Aim

The aim of this study is to explore RCH staff's perspectives on use, usability, and impact of the DöBra cards in EOL conversations with residents and/or relatives.

\section{Methods}

This qualitative study is embedded in a multi-case participatory action research (PAR) project exploring staff competence for EOL conversations in the RCH context, which is in turn part of the national DöBra[1] research program [28]. 
The project was conducted in collaboration with Stockholm City Elder Care Bureau, the municipal agency with overarching responsibility for development and follow-up of elder care provision, and the private care company Vardaga. The study thus includes both non-profit and for-profit residential elder care in Sweden. In Sweden there are two forms of residential long-term elder care: RCHs and assisted living facilities (ALFs), which generally cater to residents with fewer medical needs than RCHs. Most of the workforce is comprised of certified nursing assistants (CNAs, also called licensed practical nurses) and nursing assistants as primary caregivers, with at least one registered nurse (RN) always on site and physicians available by phone or at set hours [29,30]. Since both types of facilities provide round-the-clock access to care staff for daily assistance with e.g., hygiene routines and administration of medication, we refer to them together as RCHs. While physician-led EOL conversations are recommended in Sweden, neither binding documents nor appointment of proxies are legally admissible at present, and ACP is currently a virtually unknown concept in Swedish care.

Tools

The DöBra cards contain 37 pre-formulated statements (see [25] for statements) derived from prior research [31] and 'wild cards', which can be used to state any individual priorities not covered by the preformulated cards.

The procedure for using the cards in this study follows recommedations for the GoWish cards. The cards are sorted in three piles according to their importance to the individual, with the 10 cards chosen as most important cards thereafter ranked. Individuals are encouraged to reflect on and talk about their choices as they sort and rank the cards, providing additional information about underlying reasoning.

Ethical considerations

The study was approved by the Swedish Ethics Review Authority (ref.no 2017/488 - 31/4 and 2018/105 - 32). All participants provided written informed consent and permission to audio-record after having received written and oral information about the study.

Participants and data collection

This study is based on data generated during two different PAR processes, described below. Characteristics of participating services are provided in Table 1 and an overview of data collection processes is shown in Table 2. 
Table 1

Characteristics of participating services

\begin{tabular}{|c|c|c|c|c|}
\hline & Service & Foci of care & Organization & $\begin{array}{l}\text { Number of } \\
\text { beds }\end{array}$ \\
\hline \multirow[t]{3}{*}{$\begin{array}{l}\text { PAR process 1: Staff } \\
\text { interviews }\end{array}$} & $\mathrm{RCH} \mathrm{A}$ & Somatic care, dementia care & $\begin{array}{l}\text { Municipal, } \\
\text { non-profit }\end{array}$ & 158 \\
\hline & $\mathrm{RCH} B$ & $\begin{array}{l}\text { Somatic care, dementia care, } \\
\text { psychogeriatric care }\end{array}$ & $\begin{array}{l}\text { Municipal, } \\
\text { non-profit }\end{array}$ & 176 \\
\hline & ALF A & $\begin{array}{l}\text { Somatic care, social care and } \\
\text { activities }\end{array}$ & $\begin{array}{l}\text { Municipal, } \\
\text { non-profit }\end{array}$ & 115 \\
\hline \multirow[t]{4}{*}{$\begin{array}{l}\text { PAR process 2: } \\
\text { working group }\end{array}$} & $\mathrm{RCH} 1$ & Somatic care, dementia care & $\begin{array}{l}\text { Municipal, } \\
\text { non-profit }\end{array}$ & 55 \\
\hline & $\mathrm{RCH} 2$ & Somatic care, dementia care & $\begin{array}{l}\text { Private, for- } \\
\text { profit }\end{array}$ & 54 \\
\hline & $\mathrm{RCH} 3$ & Somatic care, dementia care & $\begin{array}{l}\text { Private, for- } \\
\text { profit }\end{array}$ & 75 \\
\hline & ALF 1 & $\begin{array}{l}\text { Somatic care, social care and } \\
\text { activities }\end{array}$ & $\begin{array}{l}\text { Municipal, } \\
\text { non-profit }\end{array}$ & 166 \\
\hline
\end{tabular}


Table 2

Overview of the data collection processes.

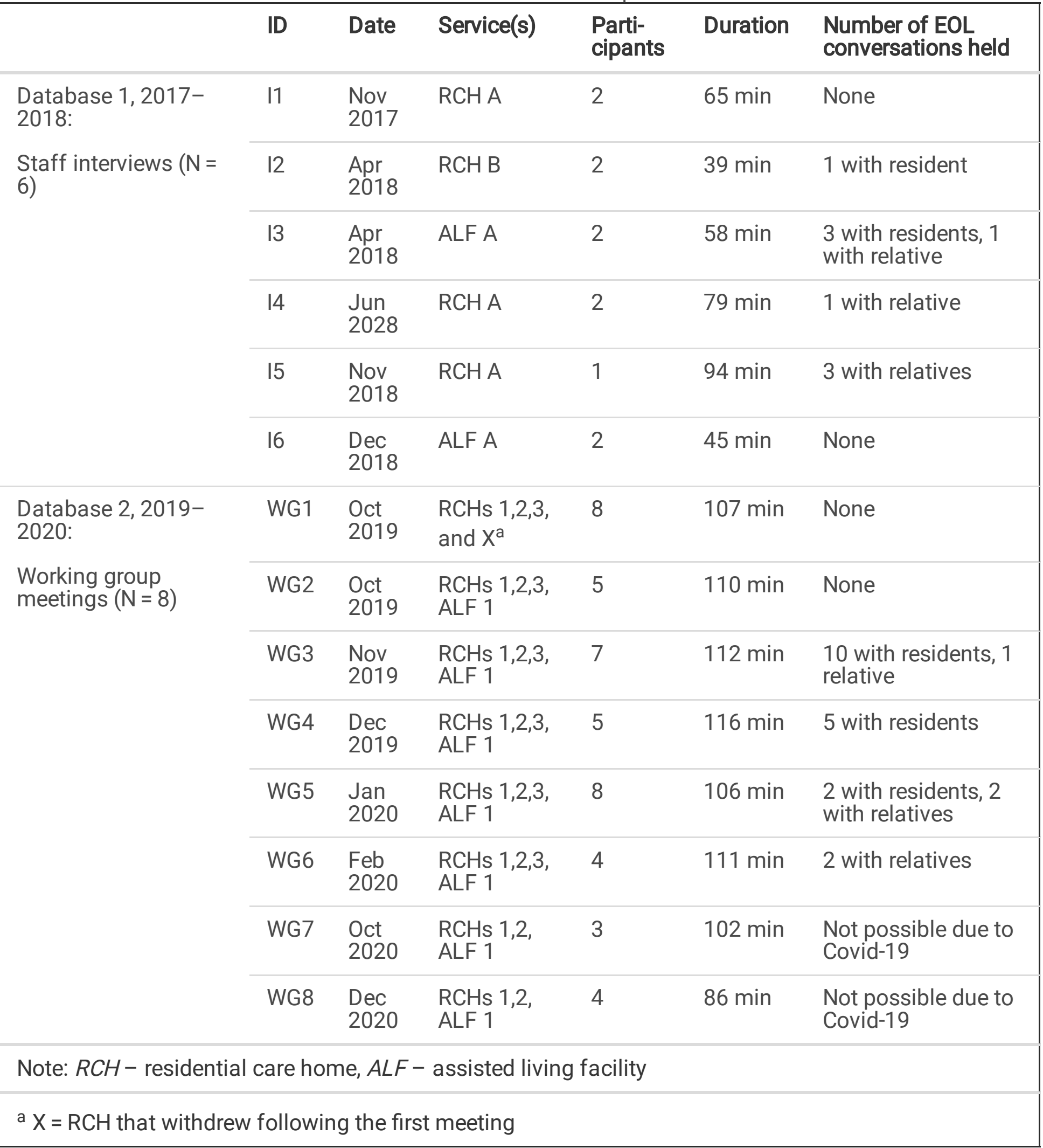

Database 1. Interviews about experiences from staff-led initiatives with the DöBra cards

The first database derives from interviews conducted in 2017-2018 with elder care staff who notified us about staff-led initiatives involving the cards in three services following participation in a previous study 
(for study details see [27]). To learn about the experiences of using the cards in the RCH setting, follow-up conversational interviews $(N=6)$ were conducted with five participants (Table 2). Interviews were audiorecorded and professionally transcribed verbatim. Authors TJ (doctoral student, MSc. in psychology) and IG (PhD and RN with an extensive background in EOL care practice and research) conducted the interviews together, with one exception, conducted by TJ alone. Both interviewers were known to the participants from the previous study [27].

Database 2. Meetings with a working group for co-developing practical guidance for EOL conversations using the DöBra cards

This database derives from meetings over time with one working group, comprising researchers and elder care staff, established in 2019. The goal was to explore how the DöBra cards might be used in EOL conversations with residents and/or relatives and co-develop practical guidance based on lessons learned. The recruitment process was two-phased. First, convenience sampling was used to invite services through existing collaborations with Stockholm City Elder Care Bureau and Vardaga. Second, a contact person in each service recruited one RN and one CNA to join the working group. Initially, four $\mathrm{RCH}$ and one ALF expressed interest in participating. However, one RCH withdrew after the first meeting, stating lack of time to fully engage. The working group thus comprised eight recurring participants from four services who tested and evaluated use of the cards in EOL conversations, discussing their experiences in regular meetings $(N=8)$ that were audio-recorded and professionally transcribed verbatim. Using topic guides informed by the cyclical PAR process of planning, action, reflection, and evaluation [32], the meetings were facilitated by authors TJ and IG, unknown to the participants prior to the study. Hosting rotated, with meetings either held in conference rooms at a university or one of the participating services. The two final meetings were conducted online using the video-conference platform Zoom, due to the Covid-19 pandemic. An overview is shown in Table 2, with details about aims and procedures for the co-development process provided in Supplement file 1. Data analysed here include meeting transcripts and minutes.

\section{Data analysis}

Inductive qualitative content analysis (QCA) was conducted to explore staff experiences of using the cards. Following each interview/meeting, author TJ wrote reflective notes which served to initiate the analytic process concurrently with ongoing data collection. Formal analysis was initiated and led by TJ who first read all transcripts to become familiar with the data. Following Kyngäs' inductive QCA [33], the analytic process followed stages of data reduction, data organization, and data abstraction. Open codes related to the research aim were constructed in NVivo.Pro (version 11) based on the meaning of the manifest content [33]. These codes were indexed and grouped based on similarity in content to form categories in an initial coding scheme that was iteratively developed and revised throughout the analytic process. To ensure analytic rigour, the coding scheme and preliminary findings were critically reviewed in discussion with all authors to discuss alternative interpretations [34]. Supplement file 2 details the full coding scheme, exemplified with the quotes used below and additional quotes. After completed analysis, 
we noted the relevance of a Theory of Change (ToC) [35] approach for conceptualizing our findings. ToC is a framework to describe how an intervention moves from input to impact, by a "backwards mapping" of intermediate outcomes acting as preconditions for long-term outcomes and the influence of contextual factors [36], which inspired the presentation of the results.

[1] "DöBra" is a Swedish pun that literally means dying well, but figuratively means awesome

\section{Results}

In total, data deriving from 11 women and 2 male staff members, aged 32-65 years, working in seven elder care services were analysed in this study. Seven were CNAs, five RNs, and one was an activity coordinator, and they had worked in elder care between $1-40$ years (median $=18$ years). Additional demographic characteristics of the participants are shown in Table 3. In the working group, attendance varied from three to eight participants/meeting (median $=5$ ), primarily due to lack of replacement staff and sick leave.

Figure 1 shows the main categories, sub-categories, and codes constructed through data analysis. Figure 2 illustrates the results in chronology and presents inter-relationships between input, output, and the main categories of the findings. Analytic points are illustrated with quotes, linked to profession and data collection stage, i.e. interview or working group meeting number, to demonstrate the link between data and findings [37] while maintaining individual partcipants' anonymity. 
Table 3

Demographic characteristics of participants in both data collection processes

\begin{tabular}{|l|l|}
\hline Participants & $\mathbf{N = 1 3}$ \\
\hline Gender & 11 \\
Women & 2 \\
\hline Men & \\
\hline Profession & 7 \\
\hline Certified nursing assistant (CNA) & 5 \\
\hline Registered nurse (RN) & 1 \\
\hline Activity coordinator & \\
\hline Education (highest qualification) & 7 \\
\hline Upper secondary education & 1 \\
\hline Higher vocational education diploma & 5 \\
\hline University diploma (>3 yrs) & \\
\hline Place of birth & 7 \\
\hline Sweden & 3 \\
\hline Europe excl. Sweden & 1 \\
\hline Africa & 1 \\
\hline Asia & 1 \\
\hline South America & \\
\hline
\end{tabular}

\section{Category 1: Outcomes of using the DöBra cards to discuss EOL values and preferences}

Participants' experiences of using the cards in EOL conversations with residents and/or relatives highlighted two main outcomes of using the DöBra cards: they outlined the conversation by providing a shared vocabulary and a framework, and supporting the development of personal connection and rapport through an intimate discussion of EOL-related values (Figs. 1 and 2).

Outlining the content of the conversation

The cards were said to provide a conversational structure, with the preformulated card statements serving as concrete examples triggering reflection and discussion. In this manner, the tool was useful for exploring care preferences in general and in detail, promoting personal stories and previous EOL 
experiences to be shared, and enabling residents and/or relatives to ask questions about EOL care provision.

\section{Identifying care values and preferences}

A central contribution of using the cards was said to relate to their support in eliciting and clarifying information about personal values that could guide person-centred care both at present and later, at the EOL. Card statements were described as concrete and straightforward, helping participants initiate EOL conversations by addressing specific matters. Residents and relatives were said to have something to react to, creating a shared point of departure for conversation. The cards were seen as stimulating reflection about EOL values and preferences and enabling these to be communicated, as suggested by this RN: "There were some statements that were chosen that you didn't know about her. ... So, some things became much clearer" (WG2). Although card statements were described as useful, some staff said the statements were too generic on their own, with conversations about them necessary to provide information specific enough to guide person-centred EOL care.

\section{Creating a forum for knowledge exchange}

The cards seemed to help make EOL conversations reciprocal learning opportunities, in which knowledge about the resident as a person and information about care routines were discussed. This is exemplified as participants in the working group discuss what EOL conversations entail:

CNA1: No, it's a conversation, actually. It's mutual and...

CNA2: [interrupting] Knowledge exchange would be more appropriate perhaps.

RN: ... it's easier, in some ways, to just conduct an interview with the cards (WG6)

Use of the cards was also described as allowing staff to explain how they could assist at the EOL. For example, one RN related how, during the card sorting, a resident was able to pinpoint a specific concern, leading to a constructive discussion about how this might be alleviated: "TThe resident] said 'I'm afraid of being scared'. ... [I said] 'in what way do you think we could help?' So we talked about that now there are medications ... that can help with anxiety and so on"(WG3). A CNA referred to a conversation in which a relative, in response to a specific card statement, started asking questions that made the participant realize how little some relatives may know about EOL care: '[the relative] asked me a very strange question. 'When my mother dies, what will happen to her?'... For us, it's so obvious, but for a relative, she didn't know" (WG5). This highlights staff's increasing awareness of the imbalance between their knowledge about EOL care and that of residents or relatives, and recognition that questions about EOL care may not be posed without opportunity to consider such issues.

Card statements also triggered sharing of personal stories, which were said to be helpful in elucidating EOL care preferences and the underlying reasoning for them. One CNA reflected on this after a conversation with a resident with a history of mental illness who had previously spoken of ending her life: 
Everyone thought she only lives in her own world, no one can trust her $100 \%$... But during the conversation, I thought, my God, she's a completely different person, why have we had preconceived notions about her instead of talking to her and understanding what kind of person we have in front of us. (WG4)

The CNA spoke of learning that the resident did not feel like she was finished living yet, triggered by the card 'to have lived my life to the fullest'. Sharing personal stories was not only said to be positive, however, as personal stories were sometimes described as "taking over" the perceived purpose of the conversation. For example, the same CNA spoke of how another resident kept coming back to his guilt about the past when sorting through the DöBra cards:

it was very difficult to complete the conversation .... He felt guilty because ... he didn't have enough time with his [deceased] wife and so on. ... [The conversation] became completely different because he only said three things that were important to him. (WG4)

Thus, sharing of EOL-related stories could provide rich information about values and preferences but might also make it more difficult for staff to direct the EOL conversations in the manner they had expected. However, the working group discussed this, suggesting using active facilitation by asking questions about other cards to lead back to discussion of EOL values.

Supporting personal connection and building rapport

As noted above, conversations about the EOL could trigger memories and existential thoughts, and participants found that some EOL conversations thus created an intimate atmosphere and a sense of rapport. In addition, the DöBra cards seemed to support a shared moment of reflection and insight that participants suggested contributed to forming a closer connection with the resident, which increased their investment in future care provision.

\section{Getting to know the resident as a person}

By promoting reflection and intimate conversation about various aspects of the EOL, the cards were said to elicit a more comprehensive understanding of the resident. Participants described how they got to know the individual on a more personal level: "I thought "how great, now I can say that I really know my resident'... [Her chosen cards reflected] her personality, for example she still always has lipstick on" (RN, WG3). EOL conversations also seemed to constitute memorable interactions in an emotional salient situation, as suggested by another RN: "I almost got the feeling that it became... something magical that you cannot put your finger on when you sit there. That you get very close to each other, like chemistry" (WG3). This closeness was discussed by the participants as a foundation for building trusting relationships with residents and/or relatives, with staff hoping that this could help make future EOL conversations easier.

Even in EOL conversations that were conducted with relatives alone, participants described getting a better sense of who the resident was as a person through detailed stories about the resident's life. 
However, participants pointed out that it could become difficult to differentiate relatives' understanding of residents' EOL values and preferences from relatives' own preferences: "That became difficult for [the relativel to keep apart, I think, what was important to him and what was important to his wife" (RN, WG6).

\section{Evoking personal engagement}

Participants spoke of how engaging in the conversations with residents and/or relatives supported mutual trust, engagement, and assurance. One RN exemplifies this, reflecting: "after you have used the cards ... it feels like if I would provide palliative care for [the resident], she'd have more confidence in me now"(WG2). At a later meeting, the same RN referred to this conversation again, suggesting it had left a lasting impression: "during my parental leave she passed away, and I've thought about what a nice meeting we had before and that I got a little closer to her then" (WG7). Participants noted that the procedure of sorting and ranking the cards sometimes led to focusing overly on the tool, limiting dynamic conversation and connection. While it was acknowledged that these experiences may still be valuable and allow individuals to reflect about rarely addressed matters, it became difficult to actively facilitate EOL conversations when the resident or relative "just... sorts cards and almost doesn't talk for half an hour"(15).

Similarly, in EOL conversations with more than one person, residents and relatives would sometimes talk amongst themselves. Such situations were said to sometimes make staff members uncertain about how to act, e.g., whether they should try to engage or simply observe and listen. One RN talked about an EOL conversation with a resident and her daughter during which the daughter read the card statements aloud for her mother and sorted them for her: "Maybe one should have played a larger role in some way ... Well, you feel ... less involved when there's another person present and they're talking a lot" (WG5).

This illustrates how less active participation may decrease participants' sense of closeness and connection with the resident and/or relative. At the same time, participants noted that such situations may contribute to closeness between those present, which was also recognized as beneficial.

\section{Category 2: Perceived impact of card use in EOL conversations}

In addition to the outcomes of card use that supported the process of EOL conversations, participants perceived more lasting impacts of card uses in EOL conversations (see Figs. 1 and 2). Such impact affected the individuals involved in the discussion and relationships between them.

Opening for continued communication

Participants generally acknowledged that EOL conversations were not one-off events but a starting point for continued reflection and discussion, which could be revisited and gradually developed further, as suggested by this CNA: 
I think this isn't just a meeting, [rather] a process that must be complemented mutually. Sometimes you [start] but you don't have time ... and you have to end the conversation ... and say "Okay, now we have started talking about it and I will return." (WG2)

The need for iterative conversations was further emphasized by participants' recognition of EOL preferences as dynamic and changing over time. By using the cards, participants highlighted that relatives could become more aware of the residents' values and preferences and residents could identify values that they might not previously have spoken about. Participants also noted how increased future communication about EOL matters between residents and relatives without staff facilitation could potentially build preparedness for future decision-making.

Aligning goals of care among stakeholders

EOL conversations using the DöBra cards were also a means to enable staff, residents, and relatives to clarify and align future goals of care at the EOL. One RN spoke about an EOL conversation with a relative who repeatedly had expressed dissatisfaction with care at the $\mathrm{RCH}$. Using the cards had provided opportunity for a discussion about what the EOL might be like for a patient with Alzheimer's disease and allowed the participant to explain how staff could work to fulfil care priorities. Soon after that conversation, the resident's health deteriorated further and the relative visited more often:

RN: I felt that somewhere he had gained more understanding. I think it was thanks to the cards because he no longer talked about needing to send her somewhere else, not even when I raised the issue....

Interviewer: How was the conversation with him?

$R N$ :... [while using the cards] he started to think out loud... that if he himself would become demented, one would hardly want anything unnecessary but would want to have peace and quiet and have things be as good as possible. ... [So] we were in full agreement in this final period, that we should try to make it calm [for her]. ... And I connected it to the cards, that we had had this shared moment. ... He said he had not thought of such things at all before. (15)

Here, the EOL conversation became the first step in connecting with a relative described as previously being confrontative with staff. The cards appeared to become a tool for creating common ground between the relative and the $\mathrm{RN}$ in terms of the resident's care, making it possible to agree on care provision at the EOL.

\section{Category 3: Factors that influence use and usability of the DöBra cards}

Several factors on the personal and contextual level facilitated or limited use of the cards and their perceived usability in this context. These factors relate to staff's personal traits and attitudes, and contextual features of both the conversation and the $\mathrm{RCH}$ organization (Fig. 1). 
Personal factors

Participants' personal traits primarily influenced cards use directly, as they affected their willingness to use the cards.

\section{Attitudes to engaging in EOL conversations}

From the outset, participants' attitudes towards EOL conversations influenced their motivation to use the DöBra cards in practice (Fig. 2). Those who originally spoke of the usefulness of EOL conversations in $\mathrm{RCH}$ s were more positive to the tool, whereas participants who seemed more sceptical about the value of EOL conversations also expressed more hesitation about testing the cards. Several participants were initially uncertain about the tool, saying the cards addressed EOL issues too directly. Over time reluctance seemed to dissipate, as one RN said: "almost all of us were also rather sceptical before, if you think about the first meeting, and now we are sitting here and are quite positive" (WG5). Hence, experience of discussing EOL issues and self-perceived competence influenced participants' use of the tool.

Participants with limited previous experience of EOL conversations and those describing death as difficult to discuss said the cards could act as a catalyst. In contrast, participants describing themselves as experienced often had their own ways of broaching the EOL. For them, the cards were occasionally said to hinder "natural" conversations, and the format and imposed structure could be described as constraining.

Another factor that affected participants differentially was the name, the DöBra cards, as it is a pun in Swedish that means both "dying well" and "awesome". Though some participants appreciated that the word death was explicit, many found the name blunt and provocative. Furthermore, the Swedish word for a deck of cards (kortlek) literally means "card game", said to further imply that EOL conversations involved playing: "[it] makes you take it less seriously and [people] may not understand the purpose because they just hear 'game', it becomes silly" (RN, WG3). While participants mentioned how some residents and relatives commented the name, participants' concern about risk being provocative generally eased over time.

\section{Facilitation style}

Participants' descriptions suggested varied facilitation styles, which in turn seemed to affect direction and depth of EOL discussions. Curiosity about the resident or relative was described as imperative as was being comfortable with emotional reactions; apprehension about triggering negative emotional reactions or damaging trust between staff and residents/relatives seemed to hinder participants' willingness to ask follow-up questions, or conduct EOL conversations at all.

Participants' ability to be flexible and adaptable to different needs and circumstances was identified as a major requirement for the cards to be useful in the $\mathrm{RCH}$ setting. Being able to give up control of the conversation and respond to the resident's/relative's reactions appeared essential: 
I understood that for her it wasn't at all important to use the cards. She simply wanted to talk ... And I listen. ... Mostly affirming [what was said]. ... No, you don't talk much. you mainly bring up the questions. (CNA, WG6)

This highlights EOL conversations as having variety of potentially valuable end-results, depending on the flexibility of the participant in facilitating a shared endeavour conducive for engaged conversations and rapport.

\section{Contextual factors}

Contextual factors, beyond individual staff member's control, affected both their possibility to conduct EOL conversations in practice as well as their perceptions of card usability.

\section{Adapting to residents' varying needs}

The variation in cognitive and physical status among $\mathrm{RCH}$ residents made it clear that the default card procedure was not always feasible or appropriate. The 37 card statements, with perceived overlap between some, were occasionally said to make the process of sorting and prioritizing cards both timeconsuming and cognitively demanding. EOL conversations with residents with cognitive decline, impaired sight, or loss of motor skills could therefore require the card exercise to be adapted, e.g., participants sometimes read the card statements aloud or turned them into questions. Participants appeared mindful of adjusting the conversation to the individual, as highlighted by one CNA: "We should help people, we shouldn't expose them to stress and anxiety and failure" (WG6). Sometimes only minor alterations were required when participants noticed that a resident was becoming tired, restless, or struggling to choose cards. For example, participants described skipping the ranking component or letting the resident/relative choose important cards without sorting them. Generally, participants argued that it was not suitable to use the cards with residents with severe dementia, perceiving greater risk of harm and lower potential gain due to the complexity of the card exercise. Instead, participants suggested that the cards could be used with relatives of such residents.

\section{Organizational prerequisites for EOL conversations}

Since EOL conversations could be emotional, participants emphasized the need for a calm, quiet, and secluded environment, preferably residents' own apartments though meetings rooms or empty activity rooms were also said to be appropriate. Being able to allot uninterrupted time was also identified as vital for maintaining presence and attentiveness: "[staff] can't do anything besides be involved in the conversation [during the allotted time]... Because you absolutely don't want to be interrupted ... so one needs to be completely spared [from other duties] for like an hour" (RN, WG6). Interruptions or having to hurry to complete the card exercise were argued to be detrimental, as both the discussion and the atmosphere would be affected. Use of disparate documentation systems between services and between staff categories within the same service hindered written communication about residents' EOL values and preferences to be shared effectively, and thus also affected usability. 


\section{Discussion}

Based on exploratory qualitative analysis of data from both non-profit and for-profit RCH and ALF services about staff experiences of using the DöBra cards to discuss future EOL care, we were able to clarify the perceived outcomes, impacts and usability of a novel EOL conversation tool. This is particularly relevant in contexts, such as Swedish elder care, where such discussions are infrequent. We found that the cards can be directly useful, by providing a framework to structure EOL conversations, helping to elicit valuable information about residents' EOL values and preferences, and enabling an interpersonal connection that strengthens rapport. In addition, our findings suggest that the cards may have more long-term impact by encouraging continued communication among stakeholders, with or without staff facilitation, and aligning care goals by supporting discussions to clarify what matters at the EOL. Factors that influenced use and usability related to both characteristics of staff members, and contextual features, based on the needs and health status of the resident involved, as well as organizational features.

Given the novelty of facilitating proactive EOL conversations in elder care, and using a conversation tool to do so, a qualitative study design was crucial to comprehensively explore staffs' experiences, and reflections regarding use and usability. Our prolonged engagement with participants may have contributed to a sense of trust for participants to openly share their insights and experiences and engagement in the study was high, suggesting that the study focus was perceived as relevant. Furthermore, using a participatory approach during data collection enabled preliminary findings to be discussed with participants throughout. This was particularly the case in the working group in Database 2 , where sharing and discussing data and initial interpretations was part of the process of co-developing the practical guidance. While member-checking does not verify results, general agreement and recognition of findings strengthens their trustworthiness [38]. Nevertheless, it should be remembered that these data reflect only participating staff's views of the EOL conversations and subsequent occurrences. It is worth noting that only staff who contacted the authors after having used the DöBra cards were interviewed for Database 1. It is possible that other staff utilized the tool without notifying us. Staff with more negative experiences might have been less likely to make contact, leading to under-representation of such experiences. Likewise, in Database 2, it is possible that participants who remained in the working group were more positive to testing an EOL conversation tool than others. Thus, self-selection may constitute a potential bias that should be remembered when considering transferability of the findings.

Unlike other, often script-based, EOL conversation tools, the cards provided examples that could be freely explored, serving as a framework stimulating in-depth reflection about EOL values and preferences. Our study adds more detailed understanding about how using a tool in EOL conversations can affect several important aspects of interaction. In addition to helping staff address and ask about residents' EOL values and preferences, the cards stimulated a reflective process and provided interactive sharing of information, stories, and emotions. These findings highlight the interpersonal aspects of EOL conversations, e.g. strengthening relationships and developing shared narratives and goals, which have been shown to act as major contributors to ACP benefit [39], particularly with older populations [40,41]. We found, as did 
Sussman et al. [42], that interactive tools, such as card games, help target reflection and can cover a variety of aspects of EOL care. However, since most EOL conversation tools focus primarily on medical aspects of care, other important dimensions risk being overlooked [42]. Prior research has suggested that non-medical issues may even be more imperative to discuss as advanced age affects care preferences [43]. As the DöBra cards cover physical, practical, existential, and social matters, they offer a more comprehensive perspective on EOL values and preferences beyond medical treatment options alone.

The DöBra cards were found to be useful to strengthen person-centered care provision and rapport both during and after EOL conversations. This is in contrast to a recent study by Groebe et al. [44], in which some care staff considered EOL conversation tools to be counterintuitive to an individualized care approach. It may be that the physical format of the DöBra cards better allowed residents and/or relatives to be actively involved in directing the discussion than other conversation tools, as the cards they choose served as route markers for mapping the discussion, with as much - or little - commentary as residents and/or relatives wished. However, this required considerable flexibility and attentiveness from staff in facilitation. Our findings thus highlight the delicate balance between seeing the cards as a tool to complete a task with a set goal on the one hand or as a trigger for an unfolding conversation in which involved parties together determine issues important to discuss on the other. This raises questions about how underlying goals of EOL conversations should be negotiated and determined. Using the cards might create forums for sharing stories or thoughts that residents and/or relatives need to express and allow discussion of topics that otherwise would not be addressed, making them meaningful experiences, even if they do not directly contribute to, or even risk hindering, completion of the card exercise as planned. We propose that staff instructions for card use need to be carefully considered as to not create perceptions of failure if the card exercise cannot be completed as suggested, which is important to consider when designing competence-building initiatives and in future research on tools for EOL conversations.

The results of this study also strongly suggest that there is no optimal 'one size fits all' procedure for using the cards and that each EOL conversation needs to be adjusted to fit the needs and constraints those participating, in line with suggestions in prior research $[45,46]$. The flexibility of DöBra card use therefore appears to be a key feature for their potential usability in RCHs and is particularly important if the tool is to be used with residents with cognitive decline. In general, EOL conversations are rarely conducted with residents with dementia [47] and participants' experiences highlighted cognitive function as a challenge, even though this study primarily involved residents who staff considered cognitively competent. The expected increase in dementia prevalence further emphasizes the need to find feasible ways to support EOL conversations also with this population $[48,49]$. In these cases, while the ranking exercise appeared too complex, the card statements were still useful as probes to clarify what matters at the EOL, as also noted by Eneslätt et al. [26]. Nevertheless, the usefulness of the DöBra cards to discuss EOL values and preferences with residents with moderate and severe cognitive impairment need to be studied further [50].

This study adds to the extant research that indicates that communication skills are a precondition for EOL conversations [51-53]. The direction and depth of EOL conversations seemed largely influenced by 
staff's interest and curiosity about what matters to other people. Additionally, the practice of 'holding space', i.e. actively listening, being mentally and emotionally present, and setting aside one's own agenda to allow the other person to lead [54] appeared to constitute a key skill for facilitating EOL conversations described as richer and more memorable. This highlights that EOL conversations differ from other conversations, by requiring staff to respond to existential needs and shift their focus from 'doing' towards

'being' and listening [55]. Building such skills may require a more experience-based approach to training, as suggested by Sand et al. [56].

The influence of contextual factors on implementation of EOL conversations is well known and this study corroborates several previously identified barriers, such as unclear mandates, under-staffing, and negative staff attitudes [57-59], as well as new prerequisites, e.g., related to systems for shared written documentation. In addition, we extend understanding about how time constraints influence not only prevalence of EOL conversations, but also their depth and salience, as stress when EOL conversations took longer than expected was a source of frustration or impatience among participants. These findings point to fundamental challenges in introducing new processes in care systems already pressed for time and resources, and as argued by Lund et al. [51], it may be that until these are dealt with, the benefits of using tools to support EOL conversations will be limited. Impact of wide-scale implementation of EOL conversations using the cards into routine $\mathrm{RCH}$ practice thus remains a critical question for future research to explore.

\section{Conclusion}

Even though proactive conversations between care recipients, their relatives and care providers to discuss values and preferences for future care have been pointed out as central for person-centered care provision at the EOL, such communication is still not widely adopted in residential elder care. This study contributes with valuable knowledge as $\mathrm{RCH}$ settings are increasingly becoming major providers of $\mathrm{EOL}$ care, as we demonstrate ways in which a novel tool, the DöBra cards, were found useful by staff to facilitate discussions about EOL values and preferences with residents and/or relatives. Direct outcomes of using the tool related both to content, i.e., elicitation of valuable information to guide future care, and interaction, i.e., development of interpersonal connection and rapport. In the long term, conversations with the DöBra cards may help prepare stakeholders for future EOL care decision-making by enabling communication and increase consensus around care goals. Specifically, this study highlights two features that appear to strengthen mutual interaction and knowledge exchange about EOL matters: a physical conversation tool format, which served as a shared structure for the discussion; and the flexibility in ways to use the DöBra cards to fit individual needs, which contributed to the helpfulness of the tool even with residents with mild cognitive decline. This combination of structure and adaptability in EOL conversations enabled residents and relatives to, together, actively direct the course and depth of the conversation using the DöBra cards.

\section{Abbreviations}


ACP - advance care planning, the formalized process of discussing and documenting preferences for future end-of-life care

ALF - assisted living facility

CNA - certified nursing assistant, also known as licensed practical nurse (LPN)

EOL - end-of-life

$\mathrm{RCH}$ - residential care home

$\mathrm{RN}$ - registered nurse

QCA - qualitative content analysis

ToC - theory of change

\section{Declarations}

\section{Ethics approval and consent to participate}

The study was approved by the Swedish Ethics Review Authority (ref.no 2017/488-31/4 and 2018/10532 ) and was conducted in accordance with the principles of the Declaration of Helsinki.

All participants provided written informed consent to participate after having received written and oral information about the study and how data would be managed and presented. All participants provided written permission to be audio-recorded.

\section{Consent for publication}

All participants in this study consented to having deidentified personal data published. Quotations are linked to professional role and data collection stage to provide a contextual and chronological perspective, but are not linked to any individual person in order protect the participants' anonymity.

\section{Availability of data and material}

The datasets used and/or analysed during the current study are available from the corresponding author on reasonable request.

\section{Competing interests}

The authors declare that they have no competing interests. 


\section{Funding}

This work was funded by Strategic Research Area Health Care Science (SFO-V), Karolinska Institutet; the Doctoral School in Health Care Sciences, Karolinska Institutet; Swedish Research Council for Health, Welfare and Working Life (FORTE); Stockholm City Elder Care Bureau; and Stockholm Gerontology Research Center. These bodies had no part in, nor influence on, the study design, data collection, analysis, interpretation, or writing of results.

\section{Authors' contributions}

All authors meet the ICMJE criteria for co-authorship, providing substantial contributions to the article. TJ and IG developed the study design and performed the data collection. TJ analysed and interpreted all data with assistance from IG, CT, JC, and LEE. TJ drafted the article. All authors participated in interpreting the study result, critically revised the manuscript and gave final approval for the final version to be published.

\section{Acknowledgements}

Not applicable.

\section{References}

1. Bone AE, Gomes B, Etkind SN, Verne J, Murtagh FEM, Evans CJ, Higginson IJ: What is the impact of population ageing on the future provision of end-of-life care? Population-based projections of place of death. Palliat Med 2018, 32(2):329-336.

2. Morin L, Aubry R, Frova L, MacLeod R, Wilson DM, Loucka M, Csikos A, Ruiz-Ramos M, CardenasTuranzas $M$, Rhee $Y$ et al: Estimating the need for palliative care at the population level: A crossnational study in 12 countries. Palliat Med 2017, 31(6):526-536.

3. Im J, Mak S, Upshur R, Steinberg L, Kuluski K: "Whatever happens, happens" challenges of end-of-life communication from the perspective of older adults and family caregivers: a Qualitative study. $B M C$ Palliat Care 2019, 18(1):1-9.

4. Martin RS, Hayes B, Gregorevic K, Lim WK: The effects of advance care planning interventions on nursing home residents: a systematic review. Journal of the American Medical Directors Association 2016, 17(4):284-293.

5. Bamford C, Lee R, McLellan E, Poole M, Harrison-Dening K, Hughes J, Robinson L, Exley C: What enables good end of life care for people with dementia? A multi-method qualitative study with key stakeholders. BMC Geriatr 2018, 18(1):302.

6. Tay DL, Ellington L, Towsley GL, Supiano K, Berg CA: Evaluation of a Collaborative Advance Care Planning Intervention among Older Adult Home Health Patients and Their Caregivers. J Palliat Med 
2020, 23(9):1214-1222.

7. Rietjens JAC, Sudore RL, Connolly M, van Delden JJ, Drickamer MA, Droger M, van der Heide A, Heyland DK, Houttekier D, Janssen DJA et al: Definition and recommendations for advance care planning: an international consensus supported by the European Association for Palliative Care. The Lancet Oncology 2017, 18(9):e543-e551.

8. Hopkins SA, Bentley A, Phillips V, Barclay S: Advance care plans and hospitalized frail older adults: a systematic review. BMJ Support Palliat Care 2020, 10(2):164-174.

9. Weathers E, O'Caoimh R, Cornally N, Fitzgerald C, Kearns T, Coffey A, Daly E, O'Sullivan R, McGlade C, Molloy DW et al: Advance care planning: A systematic review of randomised controlled trials conducted with older adults. Maturitas 2016, 91:101-109.

10. Schenell R, Ozanne A, Strang S, Henoch I: Residents' and family members' perceptions of care quality and self-determination in palliative phase in residential care. Palliative \& Supportive Care 2020, 18(1):69-81.

11. Saini G, Sampson EL, Davis S, Kupeli N, Harrington J, Leavey G, Nazareth I, Jones L, Moore KJ: An ethnographic study of strategies to support discussions with family members on end-of-life care for people with advanced dementia in nursing homes. BMC Palliat Care 2016, 15:55.

12. Mignani V, Ingravallo F, Mariani E, Chattat R: Perspectives of older people living in long-term care facilities and of their family members toward advance care planning discussions: a systematic review and thematic synthesis. Clin Interv Aging 2017, 12:475-484.

13. Threapleton DE, Chung RY, Wong SYS, Wong ELY, Kiang N, Chau PYK, Woo J, Chung VCH, Yeoh EK: Care Toward the End of Life in Older Populations and Its Implementation Facilitators and Barriers: A Scoping Review. Journal of the American Medical Directors Association 2017, 18(12):10001009.e1004.

14. Blackwood DH, Walker D, Mythen MG, Taylor RM, Vindrola-Padros C: Barriers to advance care planning with patients as perceived by nurses and other healthcare professionals: A systematic review. J Clin Nurs 2019, 28(23-24):4276-4297.

15. Evenblij K, Ten Koppel M, Smets T, Widdershoven GAM, Onwuteaka-Philipsen BD, Pasman HRW: Are care staff equipped for end-of-life communication? A cross-sectional study in long-term care facilities to identify determinants of self-efficacy. BMC Palliat Care 2019, 18(1):1.

16. Gilissen J, Pivodic L, Wendrich-van Dael A, Cools W, Vander Stichele R, Van den Block L, Deliens L, Gastmans C: Nurses' self-efficacy, rather than their knowledge, is associated with their engagement in advance care planning in nursing homes: A survey study. Palliat Med 2020, 34(7):917-924.

17. Fahner JC, Beunders AJM, van der Heide A, Rietjens JAC, Vanderschuren MM, van Delden JJM, Kars MC: Interventions Guiding Advance Care Planning Conversations: A Systematic Review. J Am Med Dir Assoc 2019, 20(3):227-248.

18. Stirling C, Mclnerney F, Andrews S, Ashby M, Toye C, Donohue C, Banks S, Robinson A: A tool to aid talking about dementia and dying - Development and evaluation. Collegian 2014, 21(4):337-343. 
19. Cardona-Morrell M, Benfatti-Olivato G, Jansen J, Turner RM, Fajardo-Pulido D, Hillman K: A systematic review of effectiveness of decision aids to assist older patients at the end of life. Patient Educ Couns 2017, 100(3):425-435.

20. Van Scoy LJ, Watson-Martin E, Bohr TA, Levi BH, Green MJ: End-of-Life Conversation Game Increases Confidence for Having End-of-Life Conversations for Chaplains-in-Training. Am J Hosp Palliat Care 2018, 35(4):592-600.

21. Jia Z, Stokes SC, Pan SY, Leiter RE, Lum HD, Pan CX: Heart to heart cards: A novel, culturally tailored, community-based advance care planning tool for Chinese Americans. American Journal of Hospice and Palliative Medicine® 2021, 38(6):650-657.

22. Menkin ES: Go Wish: a tool for end-of-life care conversations. J Palliat Med 2007, 10(2):297-303.

23. Lankarani-Fard A, Knapp H, Lorenz KA, Golden JF, Taylor A, Feld JE, Shugarman LR, Malloy D, Menkin ES, Asch SM: Feasibility of discussing end-of-life care goals with inpatients using a structured, conversational approach: the go wish card game. J Pain Symptom Manage 2010, 39(4):637-643.

24. Litzelman D, Inui T, Schmitt-Wendholt K, Perkins A, Griffin W, Cottingham A, Ivy S: Clarifying Values and Preferences for Care Near the End of Life: The Role of a New Lay Workforce. J Community Health 2017, 42(5):926-934.

25. Tishelman C, Eneslatt M, Menkin E, Lindqvist O: Developing and using a structured, conversationbased intervention for clarifying values and preferences for end-of-life in the advance care planningnaive Swedish context: Action research within the DoBra research program. Death Stud 2019:1-13.

26. Eneslätt M, Helgesson G, Tishelman C: Exploring Community-Dwelling Older Adults' Considerations About Values and Preferences for Future End-of-Life Care: A Study from Sweden. Gerontologist 2020, 60(7):1332-1342.

27. Johansson T, Tishelman C, Cohen J, Eriksson LE, Goliath I: Continuums of change in a competencebuilding initiative addressing end-of-life communication in Swedish elder care. Qual Health Res 2021:104973232110129.

28. Lindqvist O, Tishelman C: Going public: reflections on developing the DöBra research program for health-promoting palliative care in Sweden. Prog Palliat Care 2016, 24(1):19-24.

29. Nilsen P, Wallerstedt B, Behm L, Ahlström G: Towards evidence-based palliative care in nursing homes in Sweden: a qualitative study informed by the organizational readiness to change theory. Implement Sci 2018, 13(1):1.

30. Strang P, Bergström J, Lundström S: Symptom relief is possible in elderly dying COVID-19 patients: a national register study. J Palliat Med 2021, 24(4):514-519.

31. Steinhauser KE, Christakis NA, Clipp EC, McNeilly M, Mclntyre L, Tulsky JA: Factors considered important at the end of life by patients, family, physicians, and other care providers. JAMA 2000, 284(19):2476-2482.

32. Meyer J: Action Research. In: Qualitative Research in Health Care. Edited by Pope C, Mays N. Malden, Massachusetts: Blackwell Publishing Ltd; 2006: 121-131. 
33. Kyngäs H: Inductive content analysis. In: The application of content analysis in nursing science research. Springer; 2020: 13-21.

34. Hsieh H-F, Shannon SE: Three approaches to qualitative content analysis. Qual Health Res 2005, 15(9):1277-1288.

35. De Silva MJ, Breuer E, Lee L, Asher L, Chowdhary N, Lund C, Patel V: Theory of change: a theorydriven approach to enhance the Medical Research Council's framework for complex interventions. Trials 2014, 15(1):1-13.

36. Gilissen J, Pivodic L, Gastmans C, Vander Stichele R, Deliens L, Breuer E, Van den Block L: How to achieve the desired outcomes of advance care planning in nursing homes: a theory of change. $B M C$ Geriatr 2018, 18(1):47.

37. Elo S, Kyngäs H: The qualitative content analysis process. Journal of Advanced Nursing 2008, 62(1):107-115.

38. Graneheim UH, Lundman B: Qualitative content analysis in nursing research: concepts, procedures and measures to achieve trustworthiness. Nurse Educ Today 2004, 24(2):105-112.

39. Johnson SB, Butow PN, Kerridge I, Tattersall MH: What do patients with cancer and their families value most at the end of life? A critical analysis of advance care planning. Int J Palliat Nurs 2017, 23(12):596-604.

40. Hopkins SA, Lovick R, Polak L, Bowers B, Morgan T, Kelly MP, Barclay S: Reassessing advance care planning in the light of covid-19. BMJ 2020, 369:m1927.

41. Pollock K, Wilson E: Care and communication between health professionals and patients affected by severe or chronic illness in community care settings: a qualitative study of care at the end of life. Health Services and Delivery Research 2015, 3(31):1-138.

42. Sussman T, Kaasalainen S, Bimman R, Punia H, Edsell N, Sussman J: Exploration of the acceptability and usability of advance care planning tools in long term care homes. BMC Palliat Care 2020, 19(1):179.

43. Rosenfeld KE, Wenger NS, Kagawa-Singer M: End-of-life decision making. J Gen Intern Med 2000, 15(9):620-625.

44. Groebe B, Rietz C, Voltz R, Strupp J: How to Talk About Attitudes Toward the End of Life: A Qualitative Study. Am J Hosp Palliat Care 2019, 36(8):697-704.

45. Evans N, Pasman HRW, Payne SA, Seymour J, Pleschberger S, Deschepper R, Onwuteaka-Philipsen $\mathrm{BD}$ : Older patients' attitudes towards and experiences of patient-physician end-of-life communication: a secondary analysis of interviews from British, Dutch and Belgian patients. $B M C$ Palliat Care 2012, 11(1):24.

46. Hall A, Rowland C, Grande G: How Should End-of-Life Advance Care Planning Discussions Be Implemented According to Patients and Informal Carers? A Qualitative Review of Reviews. J Pain Symptom Manage 2019, 58(2):311-335.

47. Ampe S, Sevenants A, Smets T, Declercq A, Van Audenhove C: Advance care planning for nursing home residents with dementia: policy vs. practice. Journal of Advanced Nursing 2016, 72(3):569- 
581.

48. Bosisio F, Jox RJ, Jones L, Rubli Truchard E: Planning ahead with dementia: what role can advance care planning play? A review on opportunities and challenges. Swiss Med Wkly 2018.

49. Auer SR, Höfler M, Linsmayer E, Beránková A, Prieschl D, Ratajczak P, Šteffl M, Holmerová I: Crosssectional study of prevalence of dementia, behavioural symptoms, mobility, pain and other health parameters in nursing homes in Austria and the Czech Republic: results from the DEMDATA project. BMC Geriatr 2018, 18(1).

50. Siefman M, Brummel-Smith K, Baker S, Edgerton L: Consistency of Choices of End-of-Life Wishes Using the "Go Wish" cards: A comparison of elders with intact cognition and mild cognitive impairment.: B135. J Am Geriatr Soc 2013, 61.

51. Lund S, Richardson A, May C: Barriers to Advance Care Planning at the End of Life: An Explanatory Systematic Review of Implementation Studies. PLoS One 2015, 10(2):e0116629.

52. Omori M, Jayasuriya J, Scherer S, Dow B, Vaughan M, Savvas S: The language of dying: Communication about end-of-life in residential aged care. Death Stud 2020:1-11.

53. Baranska I, Kijowska V, Engels Y, Finne-Soveri H, Froggatt K, Gambassi G, Hammar T, Oosterveld-Vlug M, Payne S, Van Den Noortgate N et al: Perception of the Quality of Communication With Physicians Among Relatives of Dying Residents of Long-term Care Facilities in 6 European Countries: PACE Cross-Sectional Study. J Am Med Dir Assoc 2019, 21(3):331-337.

54. Kelemen AM, Kearney G, Groninger H: Reading the Room: Lessons on Holding Space and Presence. $J$ Cancer Educ 2018, 33(6):1362-1363.

55. Källerwald S: I skuggan av en hotad existens: om den onödiga striden mellan biologi och existens i vården av patienter med malignt lymfom [In the shadow of an endangered existence: On the unnecessary battle between biology and existence in the care of malignant lymphoma patients]. Växjö University Press; 2007.

56. Sand L, Olsson M, Strang P: Supporting in an existential crisis: A mixed-methods evaluation of a training model in palliative care. Palliat Support Care 2018, 16(4):470-478.

57. Batchelor F, Hwang K, Haralambous B, Fearn M, Mackell P, Nolte L, Detering K: Facilitators and barriers to advance care planning implementation in Australian aged care settings: A systematic review and thematic analysis. Australas J Ageing 2019, 38(3):173-181.

58. Combes S, Nicholson CJ, Gillett K, Norton C: Implementing advance care planning with communitydwelling frail elders requires a system-wide approach: An integrative review applying a behaviour change model. Palliat Med 2019:269216319845804.

59. Aasmul I, Husebo BS, Flo E: Description of an advance care planning intervention in nursing homes: outcomes of the process evaluation. BMC Geriatr 2018, 18(1).

\section{Figures}




\section{Codes}

Sub-categories

Categories

Identifying care values and preferences

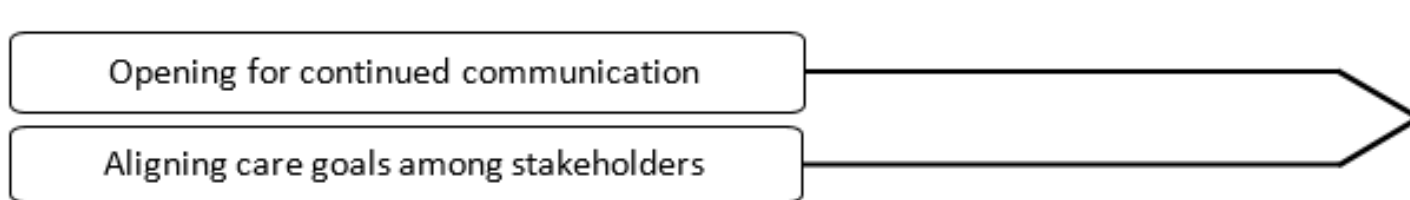

Perceived impact of card use in EOL conversations

Attitudes to engaging in EOL conversations

Facilitation style

\section{Figure 1}

Code tree showing the codes, sub-categories, and categories. 


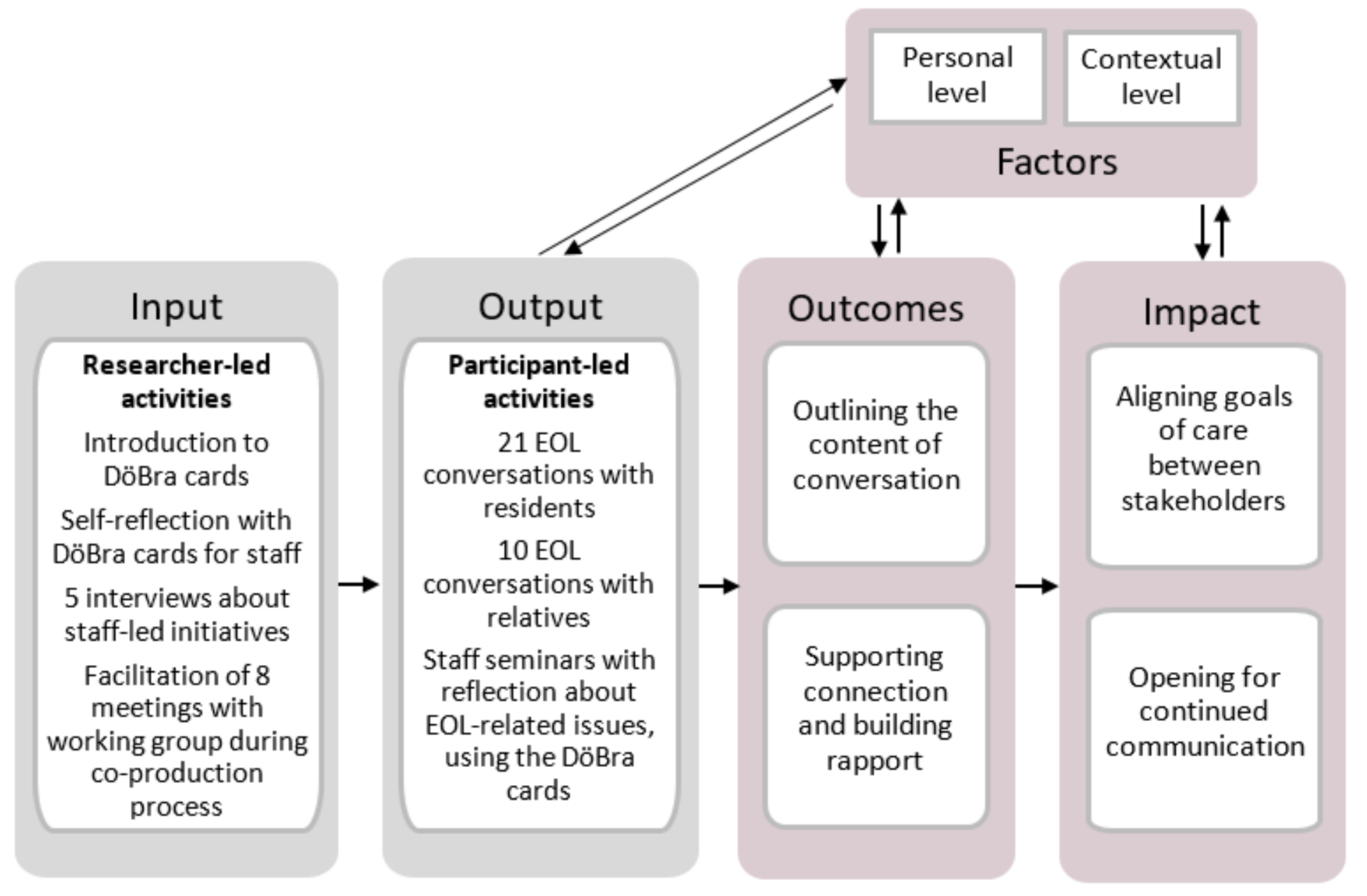

Figure 2

Schematic Theory of Change model showing project process and findings Note: Inspired by the Theory of Change (ToC) framework, we illustrate the results in relation to study input, i.e., the activities performed by researchers, and output, i.e., activities performed by participants. Arrows illustrate the influence of personal and contextual factors on output, outcomes and perceived impact of using the DöBra cards in EOL conversations in $\mathrm{RCH}$ practice.

\section{Supplementary Files}

This is a list of supplementary files associated with this preprint. Click to download.

- UseusabilityandimpactSupplementfile10verviewDatabase2.docx

- UseusabilityandimpactSupplementfile2CodematrixFINAL.docx 